Journal Club

Editor's Note: These short, critical reviews of recent papers in the Journal, written exclusively by graduate students or postdoctoral fellows, are intended to summarize the important findings of the paper and provide additional insight and commentary. For more information on the format and purpose of the Journal Club, please see http://www.jneurosci.org/misc/ifa_features.shtml.

\title{
Exploring the Origins and Development of the Visual Number Form Area: A Functionally Specialized and Domain- Specific Region for the Processing of Number Symbols?
}

\author{
Rebecca Merkley, ${ }^{1 *}$ Eric D. Wilkey, ${ }^{2 *}$ and $\odot$ Anna A. Matejko ${ }^{1 *}$ \\ ${ }^{1}$ Numerical Cognition Laboratory, Department of Psychology, University of Western Ontario, London, Ontario N6A 3K7, Canada, and ${ }^{2}$ Department of \\ Psychology and Human Development, Peabody College, Vanderbilt University, Nashville, Tennessee 37203 \\ Review of Grotheer et al.
}

The existence of a region of cortex in the ventral visual stream that responds selectively to visual presentation of numerical symbols was first postulated in the triple-code model of number processing (Dehaene, 1992). This theory proposed that there are separate neural codes dedicated to processing visual symbols, verbal representations of number, and abstract magnitudes (Dehaene, 1992). Neuroimaging studies have investigated whether a visual symbol-specific region exists by comparing brain areas activated by the visual presentation of numerical symbols with those activated by other symbol sets (Price and Ansari, 2011). However, empirical evidence for the existence of a specialized region in the ventral visual stream has only recently been reported. A region in the inferior temporal (IT) cortex that responds more to numbers than false fonts and words was first identified using electrocorticography;

Received March 3, 2016; revised March 17, 2016; accepted March 20, 2016. We thank Gavin Price, Daniel Ansari, and Jérôme Sallet for helpful comments on previous drafts.

The authors declare no competing financial interests.

*R.M., E.D.W., and A.A.M. contributed equally to this work.

Correspondence should be addressed to Eric D. Wilkey, Department of Psychology and Human Development, Peabody College, Vanderbilt University, 230 Appleton Place, Nashville, TN 37203. E-mail: eric.d.wilkey@vanderbilt.edu.

DOI:10.1523/JNEUROSCI.0710-16.2016

Copyright $\odot 2016$ the authors $\quad 0270-6474 / 16 / 364659-03 \$ 15.00 / 0$ this area was therefore named the number form area (NFA; Shum et al., 2013). Shum et al. (2013) noted that the NFA was located in a region of the inferior temporal gyrus (ITG) that is susceptible to fMRI signal dropout, which may account for the failure of previous studies to identify this location. Indeed, by using specialized methodological and processing steps to increase the mean BOLD signal intensity and the temporal signal-to-noise ratio of fMRI, Grotheer et al. (2016) recently confirmed the existence of the NFA in bilateral ITG in healthy human subjects.

The study by Grotheer et al. (2016) is significant because it demonstrates that regions in the ventral visual stream appear to be specialized for the visual processing of symbolic numbers, much like the visual word form area (VWFA) in the left fusiform gyrus is thought to be tuned to words (Cohen and Dehaene, 2004) or the fusiform face area (FFA) to faces (Kanwisher et al., 1997). However, whether areas of the IT cortex are truly domain-specific regions for processing categories of stimuli has been debated (Price and Devlin, 2003; McGugin et al., 2012). In this article, we explore whether the evidence provided by Grotheer et al. (2016) points to a genuinely domain-specific region for the visual processing of symbolic numbers and how considering the developmental origins of this region can inform this debate.

To demonstrate functional specialization of the NFA, one needs to demonstrate that it is specifically tuned to the identification of visually presented number symbols. The NFA should show greater activation for number symbols than other familiar non-numeric symbols (e.g., letters), regardless of variability in low-level visual features (eg, font, color, size) or attentional demands (Cohen and Dehaene, 2004). Grotheer et al. (2016) demonstrated that activity in a region of the bilateral ITG was greater for Arabic digits than other stimuli (letters, false numbers/ letters, objects, and noise), and that it was located in a region similar to the NFA identified in an electrophysiological investigation (Shum et al., 2013). Interestingly, the left NFA also showed greater activation for letters than false letters, suggesting that familiarity with the stimuli influenced activation (Grotheer et al., 2016). Furthermore, the authors demonstrated a high degree of overlap of the NFA and the letter form area, a region in the left fusiform gyrus adjacent to the VWFA (Thesen et al., 2012) that is more active for letters than other stimulus categories. Therefore, although the findings support the idea that populations of neurons in the bilateral ITG are involved in the identification of number symbols, they indicate that the NFA might not be 
specialized exclusively for numbers. Instead, the results suggest that letter and number processing regions are overlapping. Indeed, a recent study from the same group showed that applying transcranial magnetic stimulation to the right NFA resulted in impaired detection of both Arabic digits and letters (Grotheer et al., 2016). To determine whether letters and numbers are represented in distinct regions within the IT cortex, as well as in other brain areas implicated in visual processing of symbols (Roux et al. 2008; Price and Ansari, 2011), multivariate methods (such as multivoxel pattern analysis) should be used to investigate the distinct neural patterns associated with letters and numbers.

When investigating the functional specialization of the NFA, it is also important to consider how symbolic representations develop. Symbolic numbers (Arabic digits) are too recent of a cultural invention in the history of human evolution to have secured dedicated neural circuits through evolutionary pressures on the brain (Dehaene and Cohen, 2007). Thus, brain systems must become reorganized to process number symbols over learning and development. The neuronal recycling hypothesis predicts that brain regions become specialized for processing culturally invented symbols by co-opting existing brain systems (Dehaene and Cohen, 2007). Because symbols are learned through formal education, the development of regional preference for symbols must be experience-dependent. For example, activation in the VWFA depends on literacy and experience (Dehaene et al., 2010). Unlike adults, pre-literate children show no distinction between letters and numbers in the VWFA, even though the same region shows a preference for letters over faces in both groups (Cantlon et al., 2011). This illustrates that the VWFA is not specialized for letters over numbers before children have acquired the meanings of these symbols. This is also likely to be true for the NFA. Investigating how the NFA becomes sensitive to numerical symbols over development can elucidate the extent to which the NFA is a domain-specific region.

A recent review proposed the "biased connectivity" hypothesis as a potential explanation for the origin of specialized brain regions for visual representations of symbols (Hannagan et al., 2015). Specifically, the authors proposed that form areas (eg, VWFA, NFA, FFA) emerge in regions that exhibit greater structural connectivity with cortical circuits that are involved in the semantic processing of those forms, before gaining visual experience with symbols. This hypothesis is supported by developmental research in nonhuman primates suggesting that plasticity associated with learning new symbol categories is constrained by innate cortical organization (Srihasam et al., 2014). According to the biased connectivity hypothesis, the NFA should exhibit robust connectivity to the bilateral intraparietal sulcus (IPS), which has been established as an important region for processing numerical magnitude (Ansari, 2008). Previous research has shown that the left IPS becomes more tuned to the magnitudes of symbolic numbers as children acquire symbolic number knowledge (Emerson and Cantlon, 2015; Vogel et al. 2015), but it remains to be seen whether the development of the NFA is related to the experience-dependent changes in the IPS. Unfortunately, Grotheer et al. (2016) were not able to investigate connectivity with the IPS because their high-resolution imaging was limited to the IT lobes. Furthermore, the biased connectivity hypothesis predicts that functional and structural connectivity between the IPS and NFA precedes the acquisition of numerical symbols and constrains experience-dependent functional specialization of the NFA (Dehaene and Cohen, 2007; KarmiloffSmith, 2015). Therefore, further research is necessary to determine how connectivity between the IPS and NFA guides the functional specialization of these regions.

Based on the findings from Grotheer et al. (2016), the NFA does not exhibit selectivity for visual processing of number symbols, but rather has a relative preference for numbers and familiar symbols more generally. This distinction is important because preference does not necessarily indicate domainspecificity of the NFA. Great consideration needs to be made when making the claim that a region is specialized for a domain-specific function. Indeed, the literature to date does not provide unequivocal support for the notion that regions in the IT cortex are specialized in a modular fashion (McGugin et al. 2012). Views on modularity have changed since Dehaene (1992) first proposed the triple-code model 20 years ago and modules are now thought to be more flexible (Karmiloff-Smith,
2015). A domain-relevant approach was recently proposed as an alternative to domain-specific (modular) and domain-general theories of human development and evolution (KarmiloffSmith, 2015). Similar to the neuronal recycling hypothesis (Dehaene and Cohen, 2007), the domain-relevant theory postulates that biases are present in the brain from birth, and these biases makes certain regions sensitive to particular inputs. Specialization only emerges as a function of experience and development. This domain-relevant framework could be useful for exploring the origins of the NFA, particularly as children gain experience with numerical symbols. Investigating how initially nonspecialized regions change as a function of learning could provide fundamental insights into brain plasticity and the recruitment of existing neural circuits for the use of cultural inventions.

\section{References}

Ansari D (2008) Effects of development and enculturation on number representation in the brain. Nat Rev Neurosci 9:278-291. CrossRef Medline

Cantlon JF, Pinel P, Dehaene S, Pelphrey KA (2011) Cortical representations of symbols, objects, and faces are pruned back during early childhood. Cereb Cortex 21:191-199. CrossRef Medline

Cohen L, Dehaene S (2004) Specialization within the ventral stream: the case for the visual word form area. Neuroimage 22:466 476. CrossRef Medline

Dehaene S (1992) Varieties of numerical abilities. Cognition 44:1-42. CrossRef Medline

Dehaene S, Cohen L (2007) Cultural recycling of cortical maps. Neuron 56:384-398. CrossRef Medline

Dehaene S, Pegado F, Braga LW, Ventura P, Nunes Filho G, Jobert A, Dehaene-Lambertz G, Kolinsky R, Morais J, Cohen L (2010) How learning to read changes the cortical networks for vision and language. Science 330: 1359-1364. CrossRef Medline

Emerson RW, Cantlon JF (2015) Continuity and change in children's longitudinal neural responses to numbers. Dev Sci 18:314-326. CrossRef Medline

Grotheer M, Ambrus GG, Kovács G (2016) Causal evidence of the involvement of the number form area in the visual detection of numbers and letters. Neuroimage 132:314319. CrossRef Medline

Grotheer M, Herrmann KH, Kovács G (2016) Neuroimaging evidence of a bilateral representation for visually presented numbers. J Neurosci 36:88-97. CrossRef Medline

Hannagan T, Amedi A, Cohen L, DehaeneLambertz G, Dehaene S (2015) Origins of the specialization for letters and numbers in ventral occipitotemporal cortex. Trends Cogn Sci 19:374-382. CrossRef Medline

Kanwisher N, McDermott J, Chun MM (1997) 
The fusiform face area: a module in human extrastriate cortex specialized for face perception. J Neurosci 17:4302-4311. Medline

Karmiloff-Smith A (2015) An alternative to domain-general or domain-specific frameworks for theorizing about human evolution and ontogenesis. AIMS Neuroscience 2:91104. CrossRef Medline

McGugin RW, Gatenby JC, Gore JC, Gauthier I (2012) High-resolution imaging of expertise reveals reliable object selectivity in the fusiform face area related to perceptual performance. Proc Natl Acad Sci U S A 109: 17063-17068. CrossRef Medline

Price CJ, Devlin JT (2003) The myth of the vi- sual word form area. Neuroimage 19:473481. CrossRef Medline

Price GR, Ansari D (2011) Symbol processing in the left angular gyrus: evidence from passive perception of digits. Neuroimage 57:12051211. CrossRef Medline

Roux FE, Lubrano V, Lauwers-Cances V, Giussani C, Démonet JF (2008) Cortical areas involved in Arabic number reading. Neurology 70:210-217. CrossRef Medline

Shum J, Hermes D, Foster BL, Dastjerdi M, Rangarajan V, Winawer J, Miller KJ, Parvizi J (2013) A brain area for visual numerals. J Neurosci 33:6709-6715. CrossRef Medline
Srihasam K, Vincent JL, Livingstone MS (2014) Novel domain formation reveals protoarchitecture in inferotemporal cortex. Nat Neurosci 17:1776-1783. CrossRef Medline

Thesen T, McDonald CR, Carlson C, Doyle W, Cash S, Sherfey J, Felsovalyi O, Girard H, Barr W, Devinsky O, Kuzniecky R, Halgren E (2012) Sequential then interactive processing of letters and words in the left fusiform gyrus. Nat Commun 3:1284. CrossRef Medline

Vogel SE, Goffin C, Ansari D (2015) Developmental specialization of the left parietal cortex for the semantic representation of Arabic numerals: an fMR-adaptation study. Dev Cogn Neurosci 12:61-73. CrossRef Medline 